\title{
Ensuring the safety of breaking up and making up of freight trains
}

\author{
Nina Kovalenko ${ }^{1, *}$ and Aleksandr Borodin $^{1}$ \\ ${ }^{1}$ Russian University of Transport RUT (MIIT), 9, b.9, Obraztsova str., 127994, Moscow, Russia
}

\begin{abstract}
The article addresses the issue of the safety of breaking up and making up of freight trains. The aim of the study is the formation of a technological approach to the use of "barrier groups" of cars on marshalling tracks. For this, methods of analysis and modelling were used. The analysis of methods to prevent exiting of rolling stock beyond limits of the useful length of marshalling tracks is shown. A technology is proposed for the formation of "barrier groups" of cars on marshalling tracks as blocking devices.
\end{abstract}

\section{Introduction}

An integral part of the transportation process in railway transport is the technological work associated with yard operation at marshalling yards. To perform sorting work, various devices are widely used, among which the main ones are humps. Humps have an important role in accelerating the delivery of goods to customers, ensuring their safety, reducing downtime of cars. Therefore, in modern conditions, when the quality indicators of railway transport come first, the role of humps not only does not decrease, but becomes even greater. The results of the entire network of Russian railways depend on how efficiently and safely the hump yard operate.

According to the requirements of the Rules and norms for the design of marshalling devices on $1520 \mathrm{~mm}$ gauge railways used by Russian Railways, marshalling tracks of the classification yard with humps of large, medium and low power must be equipped with blocking devices. Blocking devices are designed to prevent spontaneous (unauthorized) exiting of moving cars (trains) beyond marshalling tracks. Blocking devices must guarantee the stopping of cars at an entrance speed of rolling stock up to $4,5 \mathrm{~m} / \mathrm{s}$. On the Russian Railways such technical means are used as joist blocking devices with remote control such as BZU-DU (Berdyaush and Yelets stations) or point jack-shaped retarders (Zabaykalsk and Luzhskaya stations). Jack-shaped retarders are actively used on the railways of China, the USA, South Africa, Germany and Austria. However, their use on the Russian railways is complicated by a number of factors, such as difficult weather conditions, as well as the significant weight of trains accumulated on marshalling tracks and the load created by them, as a result of which the jack-shaped retarders break down quickly.

An analysis of the current situation shows, that at a number of marshalling yards of the Russian Railways the profile of tracks of classification yards does not meet regulatory

\footnotetext{
*Corresponding author: nina-alex-kov@mail.ru
} 
requirements [1], and there are no blocking devices on them. As a result, during the shunting of cars from the hump, especially under adverse weather conditions, there remains a risk of such dangerous events as the cars leaving the useful length of tracks, forcing open the point, a collision, the formation of flat spots. The consequence of this was the constant buildup of excessive restrictions on the operation of humps, which in turn led to a decrease in their capacity and a decrease in productivity. Currently, at most stations of JSC "Russian Railways", "barrier groups" of cars are used as means to prevent exiting of rolling stock beyond the limits of classification (classification and departure) yard in the opposite direction from hump.

A "barrier group" is a group of cars placed and anchored by brake blocks before starting to breaking up of train on tracks of classification (classification and departure) yard, designed to prevent rolling stock from spontaneously exiting the useful length of track in the direction opposite to hump, or place of separation of cuts in the conditions of shunting by pushes.

In the process of rolling the cuts along the descending track and moving it along the marshalling track, various forces act on the release: gravity force and motion resistance force [2-4]. If the marshalling track has elements with an accelerating slope of profile, then at a certain point in time, the gravity force may exceed the motion resistance force and the cut will begin to pick up speed. The "barrier group" of cars when connected with cut should ensure that it stops within the marshalling track, taking into account the permissible displacement of the "barrier group" (fig. 1).

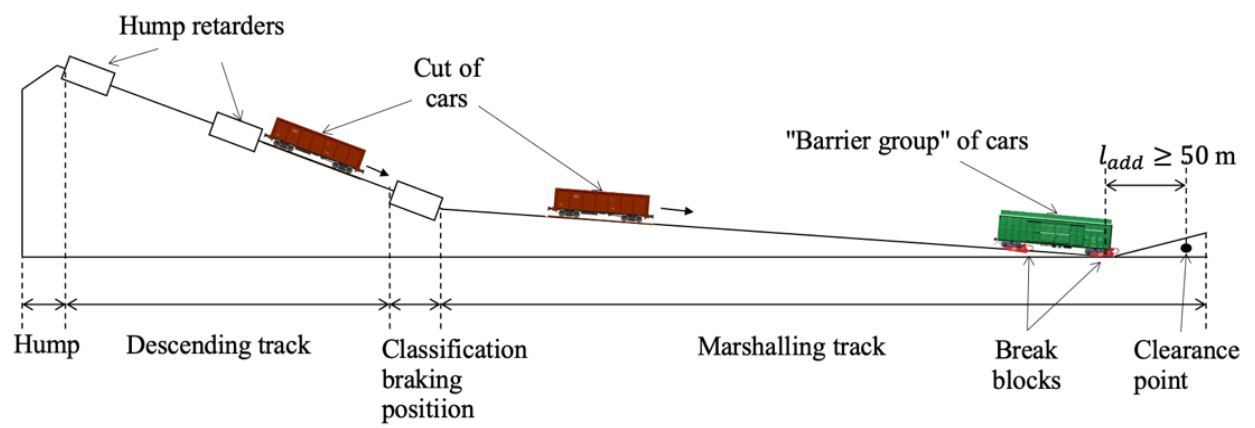

Fig. 1. Visualization of rolling-down a cut from hump with the placement of a "barrier group" of cars at the end of marshalling track.

\section{Review of literature and previous studies on this topic}

An analysis of the sources showed that there are no studies on this topic. This is primarily due to the use at the main marshalling yards outside the Russian Federation of high-tech automation systems for the sorting process [5-9]. It should be pointed out that such systems PROYARD III, SwitchPro HPC, STAR II, MSR-32 are expensive complexes, equipped with plenty of various sensors and complex systems for control of blocking devices. On the Russian railways, situation is complicated by the large geography of transportation, a large number of marshalling yards, as well as the frequent change in the direction of cargo flows, which causes a change in concentration of marshalling work. In order to refuse to form "barrier groups" of cars on marshalling tracks, yard should be equipped with modern technical facilities, and the profile of marshalling tracks should be corrected at least once a year, which is a financially demanding task, especially in conditions of a large number of marshalling yards. Currently, on the Russian Railways, in accordance with the Rules for the Technical Operation of Railways of the Russian Federation, the profile of a marshalling track 
should be checked once every three years, and accordingly, the profile will be straightened even less often.

\section{The technology of formation of "barrier groups" of cars on marshalling (marshalling and departure) tracks}

The "barrier group" is part of the train accumulated on marshalling (marshalling and departure) track and is formed from cars assigned to this track. The technology for formation of a "barrier group" of cars is established taking into account the features of technical equipment and the technology of operation of a particular marshalling yard.

\subsection{The train is accumulated on one marshalling (marshalling and departure) track}

The train is accumulated on one marshalling (marshalling and departure) track, the length of which is sufficient to accommodate the formed train of set length and "barrier group" of cars. The "barrier group" is placed and anchored at a distance $l_{\text {add }}$ from the border of the useful track length (clearance point).

In this case, the following condition:

$$
l_{\text {track }} \geq l_{\text {train }}+l_{B G}+l_{\text {add }},
$$

where $l_{\text {track }}$ - useful length of the marshalling (marshalling and departure) track, cond. car;

$l_{\text {train }}$ - the established length of the train formed on this track, cond. car;

$l_{B G}$ - the length of "barrier group" of cars, cond. car;

$l_{\text {add }}$ - additional distance from the first car of "barrier group" to the border of the useful track length used to place shunting (train) locomotive on marshalling (marshalling and departure) track taking into account the reserve to ensure safety and prevent cars exiting from the useful length of the track $l_{\text {add }} \geq 50 \mathrm{~m}(50 \mathrm{~m} \approx 3,57$ cond. car $\approx 4$ cond. car).

When condition (1) is fulfilled, the "barrier group" accumulates on marshalling (marshalling and departure) track during the accumulation of the train and is formed from the last cuts (cars) sending to this track (fig. 2.a).

After the accumulation and completion of making up a train on the tracks of classification yard, it is rearranged to the tracks of departure yard in the direction opposite to hump. Simultaneously with the rearrangement of train, cars dragging remaining on marshalling track and not included in train can be carried out to the location of "barrier group" where the train is stopped. Yardmaster, knowing the number of the rear-end car of the rearranged train, disengages "barrier group" cars left on the track and anchors them with brake blocks (fig. 2.b).

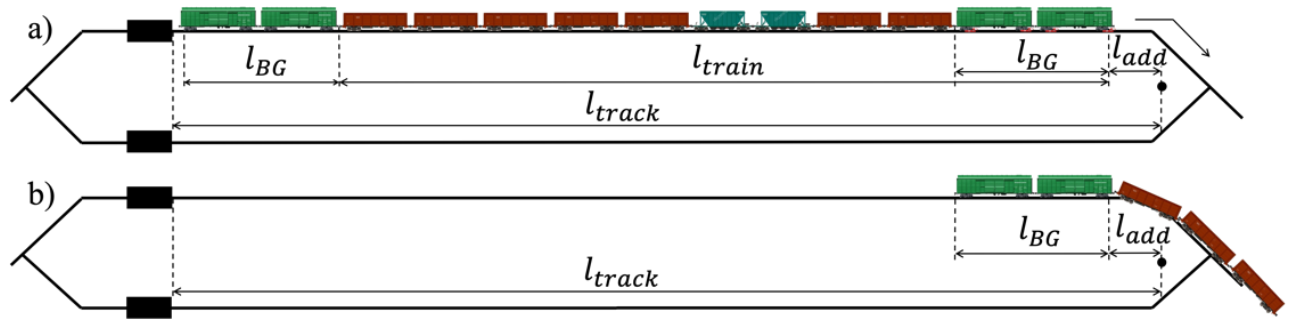

Fig. 2. The scheme of formation of the "barrier group" of cars on one track of sufficient length.

When trains depart from marshalling and departure yard [10] in the direction opposite to hump, "barrier group" of cars remains on marshalling track. After the departure of the train, 
"barrier group" is rearranged to its location (backing-up / cars dragging) with the subsequent anchoring of the cars with brake blocks.

If there is a formed and anchored "barrier group" on marshalling track in the established order, the makes-up train is first accumulated, and then cars are accumulated on the same track from hump, from which a "barrier group" will be formed for the next train.

If condition (1) is not fulfilled, the train is accumulated on one marshalling (marshalling and departure) track, the length of which is insufficient to accommodate the makes-up train of set length and "barrier group" of cars.

If after rearrangement of the train from classification yard to departure yard, or departure of the train from marshalling and departure track, there are not enough cars on marshalling track to form a "barrier group", these cars are anchored with two brake blocks placed on one rail thread from the side opposite the hump.

The formation of "barrier group" and its placement on marshalling (marshalling and departure) track will be carried out in one of the following ways:

- back-in the breaks-up train (fig. 3.a);

- dragging cars which remaining on marshalling track when rearranging the makes-up train from it to departure yard (fig. 3.b);

- backing-up from the side of hump (fig. 3.c) or by dragging cars from the exit neck of yard (fig. 3.b) remaining on marshalling and departure track after the train departure;

- rearrangement from the side of hump by shunting locomotive of the accumulated (on the other track) group of cars with its subsequent backing-up to the location of "barrier group" (fig. 3.d).

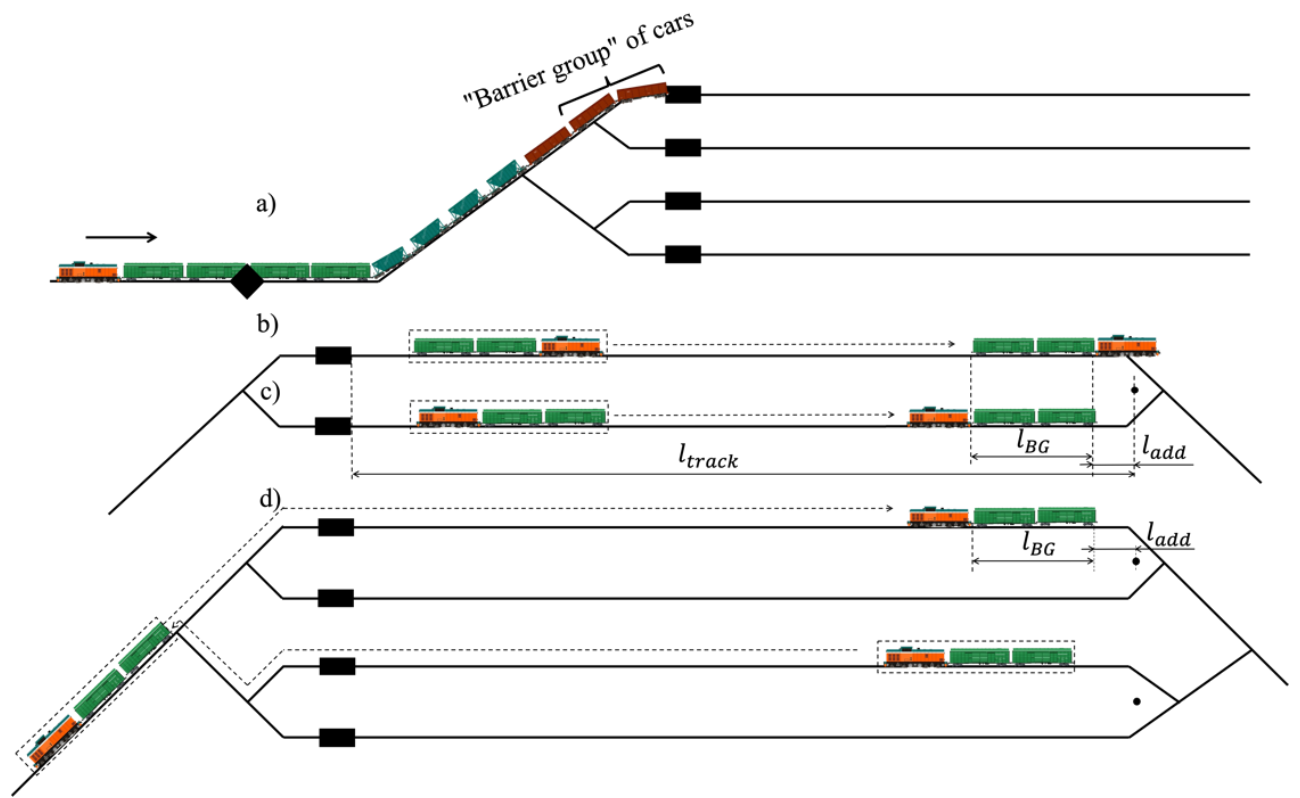

Fig. 3. Schemes for the formation of a "barrier group" of cars with insufficient track length.

\subsection{The train is accumulated on two marshalling (marshalling and departure) tracks}

If, after rearrangement of the makes-up train to departure yard (or departure of the train from classification and departure yard), one of marshalling tracks is completely released, and on the other there are cars in an amount exceeding the size of "barrier group" required for this 
track, then cars that did not enter into the "barrier group", can be rearranged by shunting locomotive to the clear track and used to form the "barrier group" on this track (fig.4).

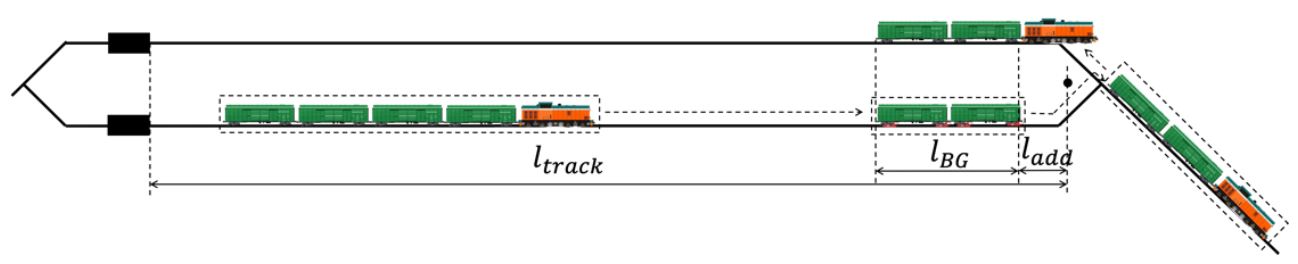

Fig. 4. The scheme of formation of the "barrier group" of cars using two tracks.

It should be noted that forbidden to be included in "barrier groups" are cars with explosive materials, tanks with liquefied gases or empty vehicles from under liquefied gases, as well as cars and / or other rolling stock with the mark "Do not shunting from the hump" or "Shunting from the hump caution".

\section{Conclusion}

This article discusses the main provisions on the formation of "barrier groups" of cars on tracks of marshalling (marshalling and departure) yard, given the definition of "barrier group" of cars. Technological features of the formation of "barrier groups" of cars are given.

\section{References}

1. K. Kornienko, S. Bessonenko, MATEC Web Conferences 216, 02012 (2018) https://doi.org/10.1051/matecconf/201821602012

2. M. Mezitis, V. Panchenko, M. Kutsenko, A. Maslii, Procedia Computer Science 149, 288-296 (2019) https://doi.org/10.1016/j.procs.2019.01.137

3. J. Prokop, Sh. Myojin, Memoirs of the Faculty of Engineering, Okayama University 27(2), 41-58 (1993)

4. J. Prokop, Sh. Myojin, Memoirs of the Faculty of Engineering, Okayama University 27(2), 59-71 (1993)

5. Trackguard Cargo MSR32 system for automation of train formation yards, //new.siemens.com/global/en/products/mobility/rail-solutions/rail-automation/yardand-depot-solutions/cargo-automation.html

6. SwitchPro - hump process control system, https://pstechnology.com/pst-yard-solutions

7. C. Worrell, Automating the industry, one yard at a time, Railway Age, No. 11, pp. 3638 (2015).

8. J. Stagl, Progressive Railroading 5, 24-30 (2009)

9. C. Zhang, Y. Wei, G. Xiao, Z. Wang, J. Fu, Traffic and Transportation Studies 2000, 285-290 (2000) https://doi.org/10.1061/40503(277)45

10. S. Gestrelius, M. Aronsson, M. Joborn, M. Bohlin, Journal of Rail Transport Planning \& Management 7(3), 157-170 (2017) https://doi.org/10.1016/j.jrtpm.2017.06.002

11. S. Ognjenovic, R. Donceva, N. Vatin. Procedia Engineering. 2015. 117(1). Pp. 544550. DOI:10.1016/j.proeng.2015.08.210. 